\title{
Benign Acute Childhood Myositis due to Toxoplasmosis
}

\author{
Şule Yıldırım ${ }^{1} \cdot$ Fatih Battal $^{1} \cdot$ Hakan Aylanç ${ }^{1} \cdot$ Mustafa Tekin $^{1} \cdot$ Nazan Kaymaz $^{1}$ • \\ Fatih Köksal Binnetoğlu ${ }^{1} \cdot$ Naci Topaloğlu ${ }^{1}$
}

Received: 8 June 2015 / Accepted: 4 November 2015 /Published online: 7 December 2015

(C) Dr. K C Chaudhuri Foundation 2015

To the Editor: A previously healthy 5-y-old boy was admitted to the emergency department with the complaint of leg pain and refusal to walk. Ten days ago he had a period of low-grade fever and fatigue that recovered spontaneously. Twenty-four hours before the admission the leg pain began and then he refused to walk. He was living in a village and had a history of contact with cats. On physical examination, he was well, afebrile and other vital signs were within normal limits. There was no lymphadenopathy or hepatosplenomegaly. Neurologic examination was normal. Extremity examination revealed bilateral calf tenderness on palpation. His gait was stiff-legged and flat-footed; he had difficulty in walking. Complete blood count and basic metabolic profile were normal. Creatine kinase (CK) increased to $809 \mathrm{U} / \mathrm{L}$, three times normal (26-308 U/L). Urinalysis was normal and negative for myoglobin. Serology was performed to establish the etiology. It supported the acute toxoplasma infection and no other agent. His serologic results for T.gondii were as following; IgG Dye test was 6000 (positive $\geq 16$ ), IgM ELISA was 10 (positive $\geq 2$ ) and IgG avidity was 1.8 (low $\leq 20$ ). He completely recovered and could walk independently on the 5th day of follow up. His CK returned to normal (126 U/L) and was diagnosed as benign childhood acute myositis (BCAM) after a toxoplasma infection.

Benign childhood acute myositisis is a muscle syndrome that is most commonly seen after a viral infection [1]. The most common presentation of the disease is acute refusal to walk or altered gait during walking. Although the most common etiologic agents are influenza type A and B viruses, the

Șule Yıldırım

sule.yildirim@comu.edu.tr

1 Department of Pediatrics, Faculty of Medicine, Çanakkale Onsekiz Mart University, 17000 Çanakkale, Turkey other agents are also reported in the literature [2,3]. Toxoplasmosis is mostly subclinical or asymptomatic infectious disease in healthy children. Myocarditis and myositis are reported as rare clinical findings [4].

The other clinical findings of BCAM are male predominance and serum CK increase. If the CK levels are too high, patient should be monitored in terms of rhabdomyolysis and renal failure [5]. Duration of symptoms are short and the recovery is spontaneous; therefore, further investigations are unnecessary unless the diagnosis is suspected [3].

In patients with acute gait disturbances if there are no alarming symptoms, BCAM should be considered certainly before unnecessary and invasive investigations. Viral serologic investigations are helpful in supporting the diagnosis.

\section{Compliance with Ethical Standards}

Conflict of Interest None.

Source of Funding None.

\section{References}

1. Zafeiriou DI, Katzos G, Gombakis N, Kontopoulos EE, Tsantali C. Clinical features, laboratory findings and differential diagnosis of benign acute childhood myositis. Acta Paediatr. 2000;89:1493-4.

2. Saltı S, Sürücü M, Özdemir Ö. Benign childhood acute myositis: clinical and laboratory findings of 15 cases. Turk Arch Ped. 2012;47: 55-8.

3. Rennie LM, Hallam NF, Beattie TF. Benign acute childhood myositis in an accident and emergency setting. Emerg Med J. 2005;22: 686-8.

4. Le Saux NMA. Toxoplasmosis. In: Rudolph CD, editor. Rudolph's pediatrics. 22nd ed. New York: McGraw-Hill; 2011 ch 354.

5. Yağcı B, Teksam O, Cengiz AB. Benign acute childhood myositis associated with influenza B infection: a case report. Çocuk Sağlığı ve Hastalıkları Dergisi. 2007;50:262-5. 